\title{
Complete or partial reduction of the Met receptor tyrosine kinase in distinct circuits differentially impacts mouse behavior
}

\author{
Barbara L. Thompson ${ }^{1,2,3^{*}}$ and Pat Levitt ${ }^{2,3}$
}

\begin{abstract}
Background: Our laboratory discovered that the gene encoding the receptor tyrosine kinase, MET, contributes to autism risk. Expression of MET is reduced in human postmortem temporal lobe in autism and Rett Syndrome. Subsequent studies revealed a role for MET in human and mouse functional and structural cortical connectivity. To further understand the contribution of Met to brain development and its impact on behavior, we generated two conditional mouse lines in which Met is deleted from select populations of central nervous system neurons. Mice were then tested to determine the consequences of disrupting Met expression.

Methods: Mating of $E m \times 1^{c r e}$ and Met ${ }^{f \times / f x}$ mice eliminates receptor signaling from all cells arising from the dorsal pallium. Met ${ }^{f x / f x}$ and Nestin ${ }^{c r e}$ crosses result in receptor signaling elimination from all neural cells. Behavioral tests were performed to assess cognitive, emotional, and social impairments that are observed in multiple neurodevelopmental disorders and that are in part subserved by circuits that express Met.

Results: Met ${ }^{f x / f x} / E m x 1^{c r e}$ null mice displayed significant hypoactivity in the activity chamber and in the T-maze despite superior performance on the rotarod. Additionally, these animals showed a deficit in spontaneous alternation. Surprisingly, Met $t^{f x / f x ; f x /+} / N^{2} s t i n^{c r e}$ null and heterozygous mice exhibited deficits in contextual fear conditioning, and Met $t^{f x /+} / N_{e s t i n}{ }^{c r e}$ heterozygous mice spent less time in the closed arms of the elevated plus maze.

Conclusions: These data suggest a complex contribution of Met in the development of circuits mediating social, emotional, and cognitive behavior. The impact of disrupting developmental Met expression is dependent upon circuit-specific deletion patterns and levels of receptor activity.
\end{abstract}

Keywords: Gene dose, Autism, Mouse, Fear learning, Behavior, Phenotype, Met

\section{Background}

Met encodes a tyrosine receptor kinase whose only known ligand is hepatocyte growth factor [1, 2]. MET signals through canonical ERK and PI3 kinase pathways, regulating neuronal development, including peripheral axon guidance, neuronal growth, and synapse development [3-8]. MET is expressed in excitatory projection neurons in a spatially and temporally limited pattern in

\footnotetext{
*Correspondence: blthomps@usc.edu

${ }^{1}$ Chan Division of Occupational Science and Occupational Therapy, Herman Ostrow School of Dentistry, University of Southern California, Los Angeles, CA 90089, USA

${ }^{2}$ Institute for the Developing Mind, Children's Hospital of Los Angeles, Keck School of Medicine, University of Southern California, Los Angeles, CA 90027, USA

Full list of author information is available at the end of the article
}

the developing primate and rodent neocortex, hippocampus, and select amygdala and septal nuclei [7, 9-13]. There is conserved enrichment in growing axons and at developing synapses $[9,10]$, with expression decreasing dramatically during the period of pruning in primate and mouse. The specific patterns of neocortical expression, however, differ substantially between primate and rodent $[10,13,14]$, suggesting possible differences in the behavioral impact of disrupted MET expression between species. A genetic reduction or elimination of $\mathrm{Met}$ increases local intralaminar excitatory drive in the mouse cerebral cortex [15] and disrupts the timing of excitatory synapse maturation in CA1 neurons in the hippocampus [8].

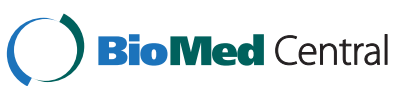

(c) 2015 Thompson and Levitt. Open Access This article is distributed under the terms of the Creative Commons Attribution 4.0 International License (http://creativecommons.org/licenses/by/4.0/), which permits unrestricted use, distribution, and reproduction in any medium, provided you give appropriate credit to the original author(s) and the source, provide a link to the Creative Commons license, and indicate if changes were made. The Creative Commons Public Domain Dedication waiver (http://creativecommons.org/publicdomain/zero/1.0/) applies to the data made available in this article, unless otherwise stated. 
Several lines of evidence have implicated $M E T$ in impacting human brain function and growth. Genetic studies have demonstrated that a $5^{\prime}$ promoter polymorphism is associated with increased risk for autism spectrum disorder (ASD) [16-19]. This risk variant is functional, reducing MET transcription in both typical and ASD subjects [20-22]. In addition, a recent study identified a family pedigree with a rare, causal heterozygous mutation in MET that was associated with ASD or socialcommunication diagnoses in the siblings [23]. In multiplex families, subjects with ASD and the MET promoter risk variant have more severe social and communication symptoms [24]. Neuroimaging studies demonstrated that the same risk variant is associated with altered functional and structural connectivity in all scanned individuals but with more impacted phenotypes in subjects with ASD compared to typical controls [25]. Finally, the risk variant also is associated with distinct gray matter growth patterns in specific regions of the human brain [26].

Though recapitulating human brain-related clinical disorders precisely in rodents is not possible, behavioral analysis is very useful for translating human genetic and functional studies with developmental, cellular, and physiological changes in animal models in which there is genetically reduced or eliminated expression of ASD risk genes [27-29]. The present studies were designed to determine whether the Met-related cellular and electrophysiological phenotypes have specific behavioral consequences. Because constitutive Met null mice are embryonic lethal [30], we generated two conditional mouse lines, deleting Met from specific neuronal populations. The $E m x 1^{\text {cre }}$ driver line [31] was used to delete Met from neurons arising in the dorsal pallium and the Nestin ${ }^{\text {cre }}$ driver line [32] to delete Met from all neural cells. We report that the behavioral phenotypes vary by line and gene dose, consistent with a complex and heterogeneous impact of reducing Met expression in specific circuits, brain circuits in the mouse.

\section{Methods}

Mice

$M e t^{f x / f x} / E m x 1^{\text {cre }}$ animals were generated as previously described [11]. Briefly, conditional $\mathrm{Met}^{\mathrm{fx} / \mathrm{fx}} / \mathrm{Emx}^{\text {cre }} \mathrm{mu}-$ tant mice were produced by mating mice homozygous for a Met allele, in which exon 16 is flanked by loxP sites originally generated in the 129SV mouse strain [33] (courtesy of Dr. Snorri Thorgeirsson, NIH/Center for Cancer Research, Bethesda, MD), to Emx1 $1^{\text {cre }}$ mice originally generated in the 129S2/SvPas strain [31] (courtesy of Dr. Kevin Jones, University of Colorado, Boulder, $\mathrm{CO}$ ) that were also heterozygous for the floxed allele $\left(\mathrm{Met}^{f x /+} / E m x 1^{\text {cre }}\right)$. Conditional Met $t^{f x / f x} /$ Nestin $^{\text {cre }}$ mutant mice were generated by mating mice homozygous for Met allele to Nestin ${ }^{\text {cre }}$ animals purchased from
Jackson Laboratory (Strain Name: B6Cg- Tg(Nes$\mathrm{cre}) 1 \mathrm{~K} \ln / \mathrm{J}$ ) that were also heterozygous for the floxed allele $\left(\mathrm{Met}^{f x /+} / \mathrm{Nestin}^{\text {cre }}\right)$. All breeding lines Met $\mathrm{f}^{f \mathrm{x} / \mathrm{fx}}$, $\mathrm{Met}^{\mathrm{fx} /+} / \mathrm{Emxl}^{\mathrm{cre}}$, and Met $\mathrm{fx}^{\mathrm{fx} /+} / \mathrm{Nestin}^{\text {cre }}$ were backcrossed onto the C57BL/ $6^{\mathrm{J}}$ background (purchased from Jackson Laboratory) for greater than 10 generations, and their progeny (i.e., $M e t^{f x / f x} / E m x 1^{c r e}$ (knockout (KO)), $M e t^{f x /+} / E m x 1^{\text {cre }}$ (heterozygous (Het)), Met $t^{f x / f x} / N^{2}$ stin $^{\text {cre }}$ (KO), Met $t^{f x /+} / \mathrm{Nestin}^{\text {cre }}$ (Het), and littermate control (wildtype (WT)) mice) were genotyped via polymerase chain reaction (PCR) as previously described [11]. The PCR primer set for cre was forward 5'-TCGATG CAACGAGTGATGAG- 3 ' and reverse $5^{\prime}$-TTC GGC TAT ACG TAA CAG GG-3' to produce a 481-bp PCR product.

Animals were housed on ventilated racks with their littermates (either WT and KO or WT, Het, and KO), with 12-h light-dark cycle (5:00 am-5:00 pm), and access to food and water ad libitum. Only adult male mice between postnatal day (P) 90 and P140 were used for behavioral analysis. All experiments conformed to the guidelines set forth by the University of Southern California Institutional Animal Care and Use Committee and the National Institutes of Health.

\section{Behavior}

A battery of behavioral tests $[28,34]$ were used to assess cognitive, emotional, and social impairments that are observed in multiple neurodevelopmental disorders, including ASD, and that are, in part, subserved by circuits that express Met developmentally [10, 11]. Additional assays were performed to assess motor capacity. The sequence of tasks was such that simple motor tasks (rotarod and activity chamber) were performed first, followed by more complex testing of baseline cognition and anxiety (elevated plus maze, marble burying, spontaneous alternation). This was followed by sociability, social novelty preference and olfactory dishabituation, and lastly contextual and cued fear conditioning. Multiple cohorts of animals were run through the battery of tests. Within each cohort, WT animals were always pair housed either with $\mathrm{KO}$ animals or, for the Met $^{f x / f x ; f x /+} /$ Nestin $^{\text {cre }}$ cohorts, with KO and Het. Our behavioral battery assessment of the $M e t^{f x \mid f x} / E m x 1^{\text {cre }}$ cohorts revealed no significant differences between Het and WT offspring; so, our breeding schema was designed to favor production of $\mathrm{KO}$ animals. All animals in a cohort (WT, KO, Hets) were run simultaneously to control for potential environmental confounds. All behavioral assays were performed during the light portion of the circadian cycle between 6:30 am and 12:30 pm. Mice were habituated to transportation to the behavior rooms located in the vivarium and acclimated for a minimum of $30 \mathrm{~min}$ before each behavioral test. All 
tasks were performed by experimenters blind to the genotype of each animal.

\section{Data analysis}

All behavioral coding and statistical analyses were performed by experimenters blind to the genotype of the animals. For tasks recorded by videotape (elevated plus maze, marble burying, T-maze, social novelty preference, and olfactory dishabituation), all behavioral codings were completed using a combination of CleverSys TopScan and Social Scan Software (CleverSys Inc., Reston, VA), and Mooses observation system [35]. For rotarod, activity chamber, contextual, and cued fear conditioning, behavioral codings were completed using the built-in software program from Med Associates for each task. Specific statistical analyses are described for each behavioral task. A $p$ value less than 0.05 was considered significant.

\section{Specific behaviors \\ Rotarod}

Performance on the rotarod was assessed to measure coordination and motor learning.

Apparatus A Med Associates ENV-575M, Five Station Rota-Rod Treadmill USB for Mouse was used. The diameter of the rotating shaft was $3.2 \mathrm{~cm}$; each lane was $5.7 \mathrm{~cm}$ wide, at an elevation of $16.5 \mathrm{~cm}$.

Steady speed testing procedure Mice were placed on the rotarod for 10 trials, 1 min each, under dim light (30 lx). The rotarod spins continuously at 32 RPM until the animal falls off the rotating shaft, thus breaking the $s$. The software calculates the latency to fall off the rotating shaft.

Accelerating testing procedure Mice were placed on the rotarod for three trials, $5 \mathrm{~min}$ each, for three consecutive days, under dim light (30 lx). The rotarod accelerates from 4 to 40 RPM for each trial until the animal falls off the rotating shaft, thus breaking the photobeam. The software calculates the latency to fall off the rotating shaft.

Steady speed analysis The amount of time the mouse spent on the rotarod per trial was calculated. A repeated measures ANOVA was used with genotype as a between subjects factor and trial as a within subjects factor. If the omnibus test detected a significant effect for genotype or genotype by behavior, a post hoc $t$ test was performed to determine the trial in which the differences occurred.

Accelerating speed analysis The amount of time the mouse spent on the rotarod was calculated for each trial.
Averages for latency to fall were calculated for each of the 3 days. A repeated measures ANOVA was used with genotype as the between subjects factor and day as the within subjects factor. If the omnibus test detected a significant effect for genotype or genotype by behavior, a post hoc $t$ test was performed to determine the day in which the differences occurred.

\section{Activity chamber}

Locomotor activity was assessed over a 30 -min period in an activity chamber that was novel for each mouse.

Apparatus Med Associates ENV-510 testing chambers within sound isolation cubicles were used. The chambers are $27 \mathrm{~cm} \times 27 \mathrm{~cm} \times 20.3 \mathrm{~cm}$ high with 16 infrared transmitters and receivers to detect movement in the $x, y$, and $z$ planes. The house light and fan in the chambers remained on for the duration of the task.

Testing procedure Mice were placed in the center of the chambers for free exploration over $30 \mathrm{~min}$.

Analysis The Med Associates Activity Monitor program detects infrared beam breaks, thus calculating total distance traveled in each plane $(\mathrm{cm})$. Distance traveled during the 30-min trial, as well as data binned into serial 5-min time periods, was calculated for each animal. A repeated measures ANOVA was used with genotype as the between subjects factor and distance traveled as the within subjects factor. If the omnibus test detected a significant effect for genotype or genotype by behavior, a post hoc $t$ test was performed to determine the time points at which differences occurred.

\section{Elevated plus maze}

To assess general anxiety, mice were tested on an elevated plus maze (EPM). Typically, mice spend greater time in the protected (closed) arms compared to the unprotected (open) arms.

Apparatus A San Diego Instruments EPM for mice was used. The maze has a height of $38.74 \mathrm{~cm}$, with each arm of the maze $5 \mathrm{~cm}$ wide, $30.5 \mathrm{~cm}$ long, and a $5 \times 5-\mathrm{cm}$ center compartment. The closed arms are protected by perimeter walls $15.24 \mathrm{~cm}$ high. The lighting intensity was set at $12 \mathrm{~lx}$ for the open arms, $1 \mathrm{~lx}$ for the closed arms, and $10 \mathrm{~lx}$ for the center.

Testing procedure Mice were placed in the center of the maze, facing an open arm and provided $5 \mathrm{~min}$ to freely explore the maze.

Analysis The number of entries into each closed and open arm, total arm entries, and the amount of time 
spent in the open and closed arms, and the center was calculated. Entries into the maze arms were defined as all four paws crossing into an arm from the center area. Entries and durations were automatically tabulated using the MazeScan suite of TopScan video analysis software (CleverSys Inc., Reston VA). Duration and entries were analyzed separately. A repeated measures ANOVA was performed for both measures with genotype as the between subjects factor and area of the maze (center or open/closed arm) as the within subjects factor. If the omnibus test detected a significant effect for genotype or genotype by behavior, a post hoc $t$ test was performed to determine at which maze location the differences occurred.

\section{Marble burying}

Marble burying was performed to assess neophobia, general anxiety, and/or repetitive behaviors [36].

Apparatus Allentown microVent wide rat cages, $39 \mathrm{~cm}$ long $\times 28.5 \mathrm{~cm}$ wide $\times 19 \mathrm{~cm}$ high, were used.

Testing procedure Animals were habituated to a novel cage with $4.5 \mathrm{~cm}$ of Sani-Chip bedding (Absorption Corp., Ferndale, WA) for $30 \mathrm{~min}$. After habituation, animals were briefly removed and 20 marbles were systematically arranged in the same test cage. Animals were then placed back into the cage and given $30 \mathrm{~min}$ to freely explore. The task was performed in a room with 30 lx lighting.

Analysis The number of marbles that was buried (minimum $50 \%$ coverage of the marble) at the end of the 30-min session was counted. A one-way ANOVA (genotype as between factor) was performed to determine statistical significance between genotypes.

\section{Spontaneous alternation in T-maze}

Spontaneous alternation in the T-maze was used to assess working memory and attention, although performance is known to be influenced by states of anxiety, arousal, and altered novelty preference $[37,38]$.

Apparatus A San Diego Instruments T-maze for mice was used. Three enclosed arms comprise the maze, two of which are $15.24 \mathrm{~cm}$ in length each, and one arm $19.05 \mathrm{~cm}$ in length. Each arm is $5.08 \mathrm{~cm}$ wide, and center area is $5.08 \mathrm{~cm}$ by $5.08 \mathrm{~cm}$. Wall height is $11.58 \mathrm{~cm}$. The arms of the maze were illuminated between 12 and $18 \mathrm{~lx}$ during testing.

Testing procedure Mice were placed in the center of the maze facing one arm and given 8 min to explore the maze. Each session was recorded by a video camera positioned above the maze. An arm visit was counted when all four paws were moved into an arm.

Analysis A triple alternation in the T-maze was defined as a visit to each of the three arms sequentially. Same arm returns (SAR) indicated that an animal returned to the same arm it had exited. Alternate arm returns (AAR) was defined as an alternation between two arms. The percent spontaneous alternation (\%SA) was calculated by dividing the number of triple alternations by the number of possible alternations [\# alternations/(\# total arm entries-2) $\times 100$ ], as described previously [39-45]. Chance performance is based on three arms with $3^{3}$ possible combination of entries, but only six of those combinations result in a triplet; thus chance is equal to $(6 / 27) * 100 \%$, or $22.2 \%$. Percent same arm and alternate arm returns (\% SAR and \% AAR) were calculated as a ratio of returns to total number of entries multiplied by 100 (SAR or AAR/total entries) "100). A one-way ANOVA (genotype as the between subjects factor) was used to determine statistical significance for total arm entries, \% SA, \% AAR, and \% SAR.

\section{Olfactory dishabituation}

Olfactory detection, habituation, and dishabituation to social and non-social odorants were measured in all mice. This specific task takes advantage of a rodent's ability to rapidly habituate to an odor, by adapting a task that has been utilized to demonstrate deficits in this modality in mutant mice [46-48]. This task is divided into five odor presentation blocks in the following order: water (baseline), non-social \#1, non-social \#2, social \#1, and social \#2. During each block, mice typically show high levels of sniffing during the first presentation of the odor, but rapidly habituate, reflected in decreased sniffing time across the second and third presentations of the same odor. When a new odor is presented, sniffing time increases (dishabituation), indicating that the mouse can distinguish between the two odors.

Apparatus An Allentown microVent mouse cage measuring $29.5 \mathrm{~cm}$ long by $18.5 \mathrm{~cm}$ wide by $13 \mathrm{~cm}$ high was used. The empty wire food rack was placed on top of the cage to hold the cotton swab during testing.

Testing procedure The mouse was placed in novel cage for a 30-min acclimation, followed by three 2-min presentations of (1) $150-\mu \mathrm{L}$ water, (2) $150-\mu \mathrm{L}$ lemon extract, (3) $150-\mu \mathrm{L}$ vanilla extract, (4) a cotton swab swabbed on the bottom of stranger mouse \#1's homecage, and (5) a cotton swab swabbed on the bottom of stranger mouse \#2's homecage. Pure lemon and vanilla extract (McCormick and Company, Inc.) were applied at full concentration. The odor presentation was counterbalanced so 
half the animals received lemon extract presentations first, followed by vanilla, and the other half of the animals had the reverse presentation. The task was performed in a room with standard lighting $(65-70 \mathrm{~lx})$ to allow for proper side view videotaping of the behavioral task.

Analysis The time spent sniffing the cotton swab was recorded for each odor presentation. A repeated measures ANOVA was performed with genotype as the between subjects factor, and odorant presented as the within subjects factor. If the omnibus test detected a significant effect for genotype or genotype by behavior, a post hoc $t$ test was performed to determine for which odorant sniffing behavior differences occurred.

\section{Social novelty preference}

Social behavior was assayed using a modified threechamber arena task. This task probes general sociability and preference for social novelty, using a welldescribed paradigm $[28,49]$ in a custom-designed three-chamber arena.

Apparatus The equipment used for this task was a custom designed Plexiglas three-chamber arena $63 \mathrm{~cm}$ long by $42 \mathrm{~cm}$ wide by $23 \mathrm{~cm}$ high. The two outer chambers are $24.5 \mathrm{~cm}$ long $\times 42 \mathrm{~cm}$ wide $\times 23 \mathrm{~cm}$ high, and the inner compartment between the two outer chambers is $11.5 \mathrm{~cm}$ long $\times 42 \mathrm{~cm}$ wide $\times 23 \mathrm{~cm}$ high. The inner compartment has two walls with small entryways $(10 \mathrm{~cm}$ high by $10 \mathrm{~cm}$ long, $14.5 \mathrm{~cm}$ from end of chamber) to allow free exploration of all three chambers when doors are in the open position. The doors measure $10.5 \mathrm{~cm} \times 28 \mathrm{~cm}$ and remain open for the duration of the experiment.

Testing procedure The experimental mouse was placed in the central compartment and given $10 \mathrm{~min}$ to explore the arena with an empty inverted wire cup (Spectrum Diversified Designs, Streetsboro, OH, USA) present in the left and right compartments. A stimulus mouse was then placed inside an inverted wire cup on one side, and the experimental mouse was allowed to explore the arena for an additional $10 \mathrm{~min}$ (sociability phase). A second novel stimulus mouse was then placed under an inverted wire cup on the opposite side, and the experimental mouse was allowed to explore the arena for another $10 \mathrm{~min}$ (social novelty preference). The task was performed in a room with $30 \mathrm{~lx}$ lighting.

Analysis The time spent in each of the three chambers and time spent investigating each of the wire cups were calculated for both phases of the test (sociability and social novelty preference). A two-way ANOVA was performed with genotype as the between subjects factor and either chamber time or time spent investigating cup as the within subjects factor during both sociability and social novelty preference trials. If the omnibus test detected a significant effect for genotype or genotype by behavior, a post hoc $t$ test was performed to determine at which maze location the differences occurred.

\section{Fear conditioning}

Learning and memory for both contextual and cuespecific fear conditioning was assayed. Cohorts of WT, $M e t^{f x / f x} / E m x 1^{c r e}, M e t^{f x / f x} / \mathrm{Nestin}^{\text {cre }}$, and $M e t^{f x /+} / \mathrm{Nestin}^{\text {cre }}$ mice were tested in contextual fear conditioning. Met $t^{f x / f x} /$ $\mathrm{Nestin}^{\text {cre }}$ and $\mathrm{Me} \mathrm{t}^{\mathrm{fx/+}} / \mathrm{Nestin}{ }^{\text {cre }}$ mice animals were also tested in the cued fear conditioning paradigm based on initial results in the contextual fear conditioning paradigm. Individual animals were tested in either the contextual or the cued fear conditioning paradigm; no animal was tested in both paradigms to avoid confounds due to the influence of one task on subsequent fear testing.

Apparatus Med Associates MED-VFC-NIR-M, NIR Video Fear Conditioning Systems for Mouse were used. Fear conditioning chambers were $30 \times 25 \times 25 \mathrm{~cm}$ housed within sound attenuating chambers.

\section{Testing procedure Contextual fear conditioning:}

Training: Animals were placed into the dark sound-attenuating cubicle and acclimated for $3 \mathrm{~min}$. Animals were then presented with five 2-s $0.5-\mathrm{mA}$ footshocks separated by 220 -s intertrial intervals. Two minutes after the last shock, mice were placed into their homecage for $24 \mathrm{~h}$.

Test: The next day, mice were placed into the same dark sound-attenuating cubicle. Animals were given $8 \mathrm{~min}$ to explore without footshocks presented.

Cued (auditory) fear conditioning

Habituation in context A: Animals were placed into the dark sound-attenuating cubicle and acclimated for $30 \mathrm{~min}$, followed by return to their homecage for $24 \mathrm{~h}$.

Training in context A: Animals were placed into the dark sound-attenuating cubicle and given $3 \mathrm{~min}$ to acclimate. Animals were then presented with five 2-s 0.3-mA footshocks that were preceded by a $30-\mathrm{s} 85-\mathrm{dB} 5-\mathrm{kHz}$ tone that terminated simultaneously with the termination of the footshock. Footshocks were separated by 180-s intertrial intervals. Three minutes after the last shock, mice were returned to their homecage for $24 \mathrm{~h}$.

Contextual test in context A: Animals were placed into the dark sound-attenuating cubicle for $8 \mathrm{~min}$ and then returned to their homecage for $20 \mathrm{~min}$ before the cue test.

Cue test in context B: Animals were placed into the dark sound-attenuating cubicle with new floor and wall inserts to change the appearance of the cubicle and given $3 \mathrm{~min}$ to acclimate. Animals were then presented with 10 presentations of the $30-\mathrm{s} 85-\mathrm{dB} 5-\mathrm{kHz}$ tone 
separated by $60-\mathrm{s}$ intertrial intervals. One minute after the last tone, animals were returned to their homecage for $24 \mathrm{~h}$.

Extinction tests in context B: Animals were placed into the dark sound-attenuating cubicle with new floor and wall inserts to change the appearance of the cubicle and given $3 \mathrm{~min}$ to acclimate. Animals were then presented with 10 presentations of the $30-\mathrm{s} 85-\mathrm{dB} 5-\mathrm{kHz}$ tone separated by 60 -s intertrial intervals. One minute after the last tone, animals were returned to their homecage.

Analysis Video freeze by Med Associates was used to calculate percent time spent freezing during learning and memory trials of contextual and cued fear conditioning. A repeated measures ANOVA was performed with genotype as the between subjects factor and freezing during trials as the within subjects factor. If the omnibus test detected a significant effect for genotype or genotype by behavior, a post hoc $t$ test was performed to determine during which trials the differences occurred.

\section{Results and discussion}

Multiple cohorts of animals were run within the same animal vivarium. Within each cohort, there were always matched WT and $\mathrm{KO}$ (and Het for Nestin ${ }^{\mathrm{cre}}$ ) run simultaneously to control for possible environmental confounds. All cohorts were collapsed into a single dataset for each driver line $\left(E m x 1^{\text {cre }}\right.$ or Nestin $\left.{ }^{\text {cre }}\right)$ as there were no statistically significant differences in patterns of data generated between cohorts. Data are presented separately for the $M e t^{f x / f x} / E m x I^{\text {cre }}$ line and the $M e t^{f x / f x ; f x /+} /$ Nestin $^{\text {cre }}$ line.

\section{$\mathrm{Met}^{\mathrm{f} / \mathrm{fx} / \mathrm{Emx} 1^{\text {cre }}}$}

Animals that were homozygous null for Met in structures that are derived from the dorsal pallium (including excitatory projection neurons in neocortex, olfactory bulb, CA1 neurons of the hippocampus, and cortical amygdala region) were tested in the battery of behavioral tests described above.

\section{Steady speed rotarod}

$M e t^{f x / f x} / E m x 1^{\text {cre }}$ KO animals demonstrated better performance on the rotarod compared to their WT littermates, $F(1,52)=4.245, p<0.05$ (Fig. 1). Both groups showed consistent improved performance across the 10 trials, $F(9,468)=18.990, p<0.0001$. There was no interaction effect between genotype and trials, $F(9,468)=$ 1.063, $p>0.05$.

\section{Accelerating rotarod}

A two-way repeated measures ANOVA revealed no significant differences between genotypes for motor learning on the accelerating rotarod, $p>0.05$ (Table 1).

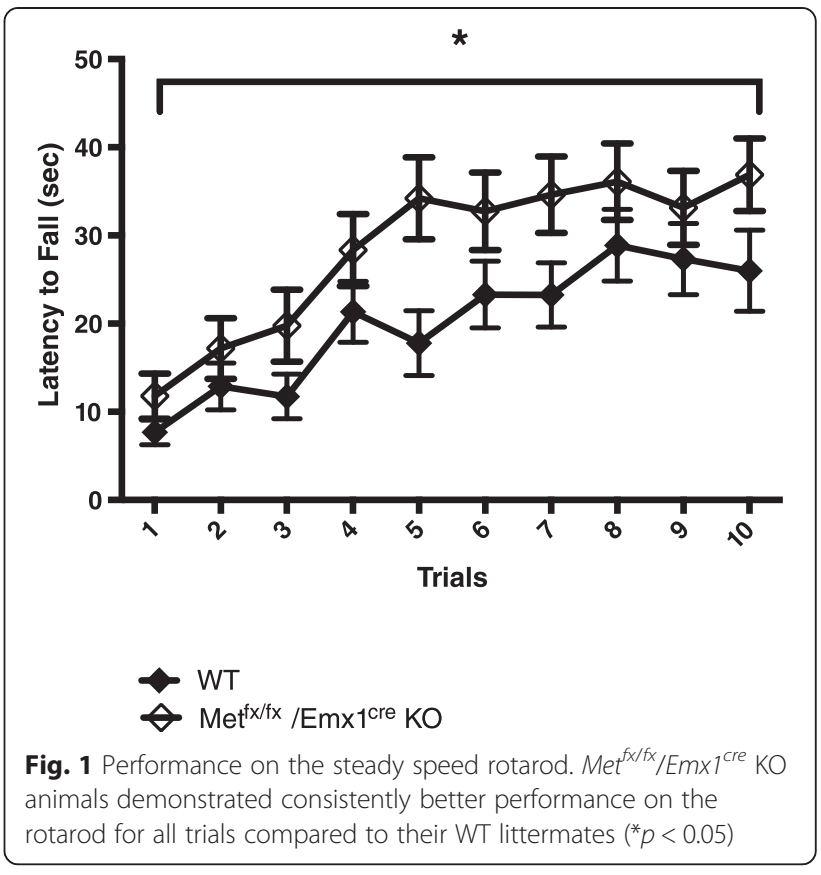

Both groups showed consistent improved performance across the 3 days, $p<0.0001$. There was no interaction effect between genotype and days, $p>0.05$.

\section{Activity chamber}

$M e t^{f x / f x} / E m x 1^{\text {cre }} \mathrm{KO}$ animals were hypoactive compared to their WT littermates, with a statistically significant main effect for genotype, $F(1,51)=12.260, p<0.005$ (Fig. 2). There was a main effect for time, $F(5,255)=$ $4.308, p<0.001$, with all animals, independent of genotype, displaying more exploratory behavior at the beginning of the 30-min trial, followed by reduced exploration. Additionally, there was an interaction effect, $F(5,255)=3.184, p<0.01$, with the WT animals exhibiting more exploratory behavior during the first $5 \mathrm{~min}$, then tapering off. In contrast, the $\mathrm{KO}$ animals showed a more consistent activity level across the 30-min task.

\section{Elevated plus maze}

$M e t^{f x / f x} / E m x 1^{\text {cre }} \mathrm{KO}$ animals did not exhibit anxiety-like behavior in the EPM task (Table 1). Separate two-way ANOVAs were performed for duration and arm entries in the EPM. For duration, there was no main effect for genotype, $p>0.05$. There was a main effect for location in the maze, with animals of both genotypes spending more time in the closed arms, $p<0.0001$. Furthermore, there was no interaction between genotype and arm location, $p>0.05$. Similarly, analysis of arm entries revealed there was no main effect for genotype, $p>0.05$. There was a main effect for location in the maze, with all animals spending more time in the closed arms than open 
Table 1 Behavioral characterization of WT and Met ${ }^{\mathrm{fx} / \mathrm{fx}} / \mathrm{Em} \mathrm{E} 1^{\mathrm{cre}} \mathrm{KO}$ mice

\begin{tabular}{|c|c|c|c|c|}
\hline & WT & 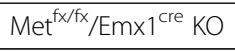 & F or $t$ Statistic & $p$ value \\
\hline \multicolumn{5}{|l|}{ Activity chamber } \\
\hline & & & Genotype, $F(1,51)=12.26$ & $p<0.05$ \\
\hline \multirow[t]{2}{*}{ Total distance traveled(cm) } & $3317.67 \pm 218.98$ & $2339.74 \pm 175.11$ & Time, $F(5,255)=4.308$ & $p<0.001$ \\
\hline & & & Interaction, $F(5,255)=3.184$ & $p<0.01$ \\
\hline \multicolumn{5}{|l|}{ Steady speed rotarod } \\
\hline & & & Genotype, $F(1,52)=4.249$ & $p<0.05$ \\
\hline \multirow[t]{2}{*}{ Average latency to fall(sec) } & $20.0185 \pm 2.58$ & $28.481 \pm 3.19$ & Trial, $F(9,468)=18.99$ & $p<0.0001$ \\
\hline & & & Interaction, $F(9,468)=1.063$ & $p>0.05$ \\
\hline \multicolumn{5}{|l|}{ Accelerating rotarod } \\
\hline & & & Genotype, $F(1,12)=0.017$ & $p>0.05$ \\
\hline \multirow[t]{2}{*}{ Average latency to fall(sec) } & $151.43 \pm 19.82$ & $148.10 \pm 16.14$ & Trial, $F(2,24)=15.35$ & $p<0.0001$ \\
\hline & & & Interaction, $F(2,24)=0.024$ & $p>0.05$ \\
\hline \multicolumn{5}{|l|}{ T-maze } \\
\hline$\%$ SA & $54.701 \pm 1.679$ & $47.4956 \pm 2.401$ & $t_{51}=2.475$ & $p<0.05$ \\
\hline$\%$ AAR & $35.063 \pm 1.554$ & $38.576 \pm 1.599$ & $t_{51}=-1.576$ & $p>0.05$ \\
\hline$\%$ SAR & $3.891 \pm 0.666$ & $5.301 \pm 0.907$ & $t_{51}=-1.410$ & $p>0.05$ \\
\hline \#arm entries & $35.852 \pm 2.456$ & $29.154 \pm 1.859$ & $t_{51}=2.162$ & $p<0.05$ \\
\hline Marble burying (\#) & $7.100 \pm 1.567$ & $9.200 \pm 1.756$ & $t_{18}=0.8923$ & $p>0.05$ \\
\hline \multicolumn{5}{|l|}{ EPM entries (\#) } \\
\hline & & & Genotype, $F(1,32)=0.2539$ & $p>0.05$ \\
\hline Closed arms & $9.188 \pm 1.697$ & $8.882 \pm 1.364$ & Arm entry, $F(1,32)=65.93$ & $p<0.05$ \\
\hline Open arms & $1.706 \pm 0.803$ & $0.5882 \pm 0.298$ & Interaction, $F(1,32)=0.2081$ & $p>0.05$ \\
\hline \multicolumn{5}{|l|}{ EPM arm duration (\%) } \\
\hline & & & Genotype, $F(1,32)=0.3463$ & $p>0.05$ \\
\hline Closed arms & $88.882 \pm 3.169$ & $86.863 \pm 5.017$ & Arm duration, $F(1,32)=220.8$ & $p<0.0001$ \\
\hline Open arms & $4.3137 \pm 1.505$ & $3.000 \pm 1.649$ & Interaction, $F(1,32)=0.2508$ & $p>0.05$ \\
\hline \multicolumn{5}{|l|}{ Sociability (sec) } \\
\hline & & & Genotype, $F(1,52)=1.463$ & $p>0.05$ \\
\hline Side with mouse & $312.897 \pm 14.864$ & $317.225 \pm 11.721$ & Chamber side, $F(1,52)=74.25$ & $p<0.05$ \\
\hline Side with empty cup & $185.271 \pm 12.428$ & $162.44 \pm 11.885$ & Interaction, $F(1,52)=0.6864$ & $p>0.05$ \\
\hline \multicolumn{5}{|l|}{ Social novelty (sec) } \\
\hline & & & Genotype, $F(1,52)=0.001$ & $p>0.05$ \\
\hline Familiar mouse side & $227.609 \pm 13.819$ & $235.362 \pm 17.602$ & Chamber side, $F(1,52)=1.545$ & $p>0.05$ \\
\hline Novel mouse side & $259.723 \pm 14.579$ & $252.667 \pm 14.533$ & Interaction, $F(1,52)=0.1387$ & $p>0.05$ \\
\hline \multicolumn{5}{|l|}{ Sociability (sec) } \\
\hline & & & Genotype, $F(1,52)=0.005652$ & $p>0.05$ \\
\hline Cup with mouse & $62.795 \pm 4.653$ & $60.152 \pm 5.095$ & Cup, $F(1,52)=214.6$ & $p<0.05$ \\
\hline Empty cup & $11.818 \pm 1.606$ & $12.645 \pm 1.254$ & Interaction, $F(1,52)=0.2665$ & $p>0.05$ \\
\hline \multicolumn{5}{|l|}{ Social novelty (sec) } \\
\hline & & & Genotype, $F(1,52)=0.02144$ & $p>0.05$ \\
\hline Cup with familiar mouse & $23.087 \pm 3.234$ & $21.624 \pm 2.801$ & Cup, $F(1,52)=63.83$ & $p<0.05$ \\
\hline Cup with novel mouse & $46.756 \pm 5.329$ & $46.817 \pm 4.221$ & Interaction, $F(1,52)=0.06198$ & $p>0.05$ \\
\hline
\end{tabular}


Table 1 Behavioral characterization of WT and Met $\mathrm{f}^{\mathrm{f} / \mathrm{fx}} / \mathrm{Em} \times 1^{\text {cre }} \mathrm{KO}$ mice (Continued)

\begin{tabular}{|c|c|c|c|c|}
\hline \multicolumn{5}{|c|}{ Contextual fear (\%) } \\
\hline Baseline & $0.04976 \pm 0.0497$ & $0.3007 \pm 0.1955$ & Genotype, $F(1,31)=0.6584$ & $p>0.05$ \\
\hline Training & $28.73 \pm 3.2649$ & $32.72 \pm 2.6444$ & Trial, $F(2,62)=110.5$ & $p<0.0001$ \\
\hline Test & $29.04 \pm 3.2954$ & $30.81 \pm 3.4346$ & Interaction, $F(2,62)=0.3224$ & $p>0.05$ \\
\hline
\end{tabular}

arms, $p<0.05$. Furthermore, there was no interaction between genotype and location in the maze, $p>0.05$.

\section{Marble burying}

There was no anxiety-like nor repetitive behaviors exhibited by $M e t^{f x / f x} / E m x 1^{c r e} \mathrm{KO}$ animals in this task (Table 1). A $t$ test revealed no significant difference between genotypes for the total number of marbles buried at the end of the 30-min trial, $p>0.05$.

\section{T-maze}

$M e t^{f x / f x} / E m x 1^{\text {cre }}$ KO animals showed significant impairment in spontaneous alternation, $t_{51}=2.475, p<0.05$ (Fig. 3a). However, neither alternate arm returns nor same arm returns were significantly different between groups, $t_{51}=-1.576, p>0.05$, and $t_{51}=-1.259, p>0.05$, respectively. Consistent with their hypoactivity in the activity chamber, $\mathrm{KO}$ animals also displayed reduced exploration in the T-maze, with significantly diminished total arm entries, $t_{51}=2.162, p<0.05$ (Fig. 3b). Because spontaneous alternation, alternate arm, and same arm returns were calculated by including total arm entries as a moderator, the decreased locomotor activity in the T-maze was not a confounder of the spontaneous alternation findings.

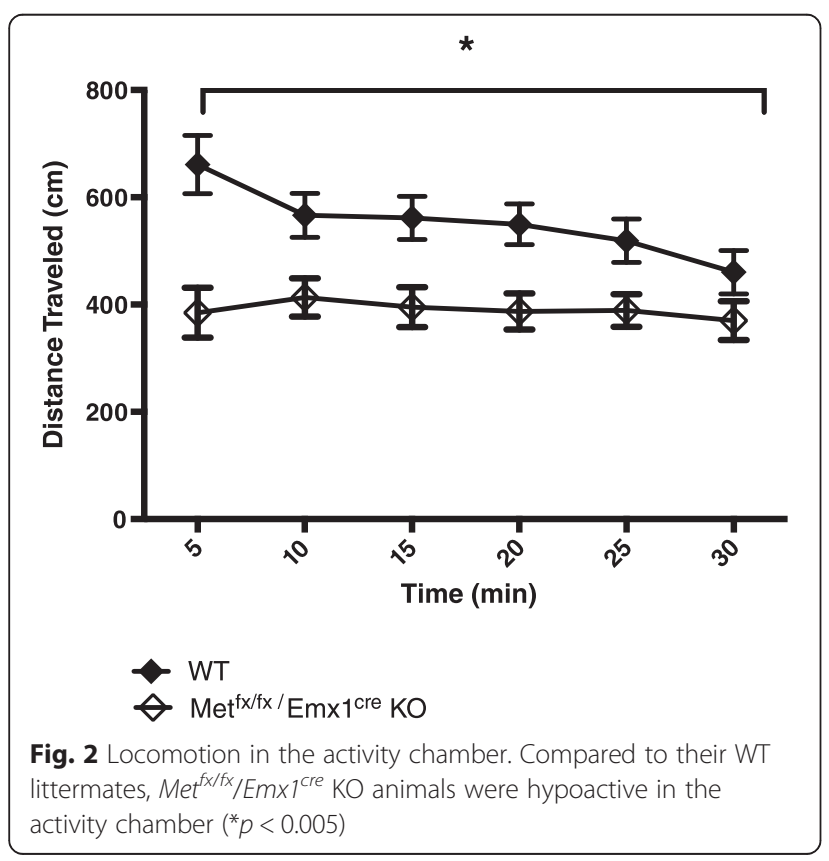

\section{Sociability and social novelty preference}

Overall, there were no differences in either sociability scores or in social novelty preference scores between $M e t^{f x / f x} / E m x 1^{c r e} \mathrm{KO}$ and WT animals (Table 1). Time in each chamber and time sniffing specific cups were analyzed separately. For chamber time, during the sociability trial, there was no main effect for genotype, $p>0.05$. There was a main effect for chamber location during sociability $p<0.05$, with all animals spending more time in the chamber with the stimulus mouse. Furthermore, there was no interaction effect, $p>0.05$. For chamber time, during the social novelty preference trial, there was no main effect for genotype, $p>0.05$. Interestingly, there also was no main effect for chamber location, $p>0.05$. Furthermore, there was no interaction effect, $p>0.05$. In comparing cup-sniffing times, there also were no differences either in sociability or in social novelty preference scores between the two groups. Both groups of animals spent more time sniffing the cup with the stimulus mouse, $p<0.05$, and there was no main effect for genotype during the sociability trial, $p>0.05$. Furthermore, there was no interaction between genotype and cup sniffing, $p>0.05$. During the social novelty preference trial, both groups of animals spent more time sniffing the cup with the novel mouse, $p<0.05$, but there was no main effect for genotype, $p>0.05$. Additionally, there was no interaction between genotype and cup sniffing, $p>0.05$.

\section{Olfactory dishabituation}

A two-way repeated measures ANOVA revealed there were no significant differences between genotypes for sniffing behaviors during the olfactory test, $p>0.05$ (Table 1).There was a significant main effect for trial, $p<0.001$, with the social trials eliciting more sniffing time. Furthermore, there was no interaction effect, $p>0.05$, with both groups of animals spending similar times sniffing odorants.

\section{Contextual fear conditioning}

A repeated measures ANOVA for fear conditioning revealed no significant differences between genotypes, $p>0.05$ (Table 1). There was a main effect for fear conditioning trial, $p<0.0001$, with all animals displaying significantly increased freezing during the training and retention test compared to baseline. Furthermore, there was no interaction between genotype and trial, $p>0.05$. 


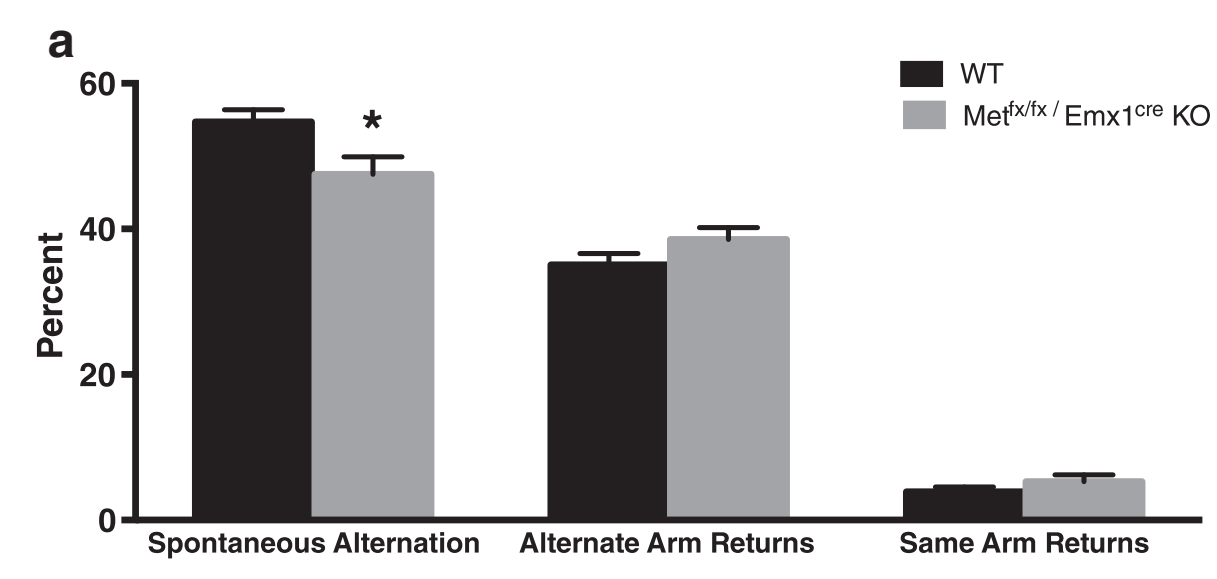

b

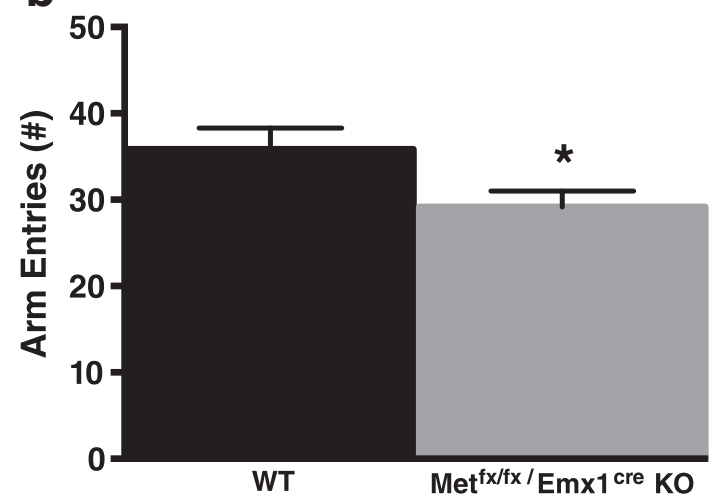

Fig. 3 Spontaneous alternation in the T-maze. a Met ${ }^{f x / f x} / E m x 1^{c r e} \mathrm{KO}$ animals showed significant impairment in percent spontaneous alternation,

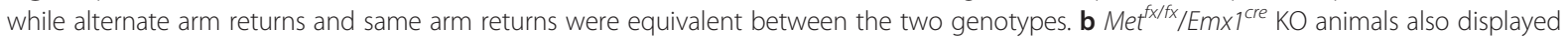
reduced exploration in the T-maze compared to $\mathrm{WT}$ animals $\left({ }^{*} p<0.05\right)$

Met $^{\mathrm{fx} / \mathrm{fx} ; \mathrm{fx} /+} /$ Nestin ${ }^{\text {cre }}$

Animals that were either heterozygous $\left(\mathrm{Met}^{\mathrm{fx} /+}\right)$ or homozygous $\left(M e t^{f x / f x}\right)$ null for Met in peripheral and central neural structures were tested in the behavioral battery described above.

\section{Steady speed rotarod}

In contrast to the $M e t^{f x / f x} / E m x 1^{\text {cre }}$ KO mice, a two-way repeated measures ANOVA revealed no significant differences between any of the Nestin ${ }^{\text {cre }}$-derived genotypes for performance on the rotarod, $p>0.05$ (Table 2). All animals showed improved performance across trials, $p<0.0001$. Furthermore, there was no interaction effect between genotype and rotarod trials, $p>0.05$.

\section{Accelerating rotarod}

A two-way repeated measures ANOVA revealed no significant differences between genotypes for motor learning on the accelerating rotarod, $p>0.05$ (Table 2). All animals showed consistent improved performance across the 3 days, $p<0.0001$. Furthermore, there was no interaction effect between genotype and days, $p>0.05$.

\section{Activity chamber}

Whereas the $M e t^{f x / f x} / E m x 1^{\text {cre }}$ KO mice exhibited activity differences compared to WT, a two-way repeated measures ANOVA revealed no significant differences between any of the $\mathrm{Nestin}^{\text {cre }}$-derived genotypes, $p>0.05$, indicating that there was no difference in total distance traveled by all animals (Table 2). Additionally, all animals, independent of genotype, displayed more exploratory behavior at the beginning of the 30-min trial and then reduced their exploration, with a main effect for time $p<0.0001$. Furthermore, there was no interaction effect between genotype and time in activity chamber, $p>0.05$.

\section{Elevated plus maze}

Separate two-way repeated measures ANOVAs were performed for both duration and entries in the EPM (Table 2). For duration, there was no main effect for genotype, $p>0.05$. There was a main effect for location in the maze, all animals spent more time in the closed arms, $p<0.0001$. In contrast to the findings with the $M e t^{f x / f x} / E m x 1^{c r e} \mathrm{KO}$ mice, there was a significant interaction between genotype and arm location, $p<0.005$. A 
Table 2 Behavioral characterization of WT, Met ${ }^{\mathrm{fx} /+} / \mathrm{Nestin}^{\text {cre }}$ Het, and Met ${ }^{\mathrm{fx} / \mathrm{fx}} / \mathrm{Nestin}^{\text {cre }} \mathrm{KO}$ mice

\begin{tabular}{|c|c|c|c|c|c|}
\hline & WT & $\mathrm{Met}^{\mathrm{fx} /+} / \mathrm{Nestin}{ }^{\text {cre }} \mathrm{Het}$ & 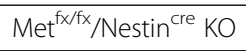 & F Statistic & $p$ value \\
\hline \multicolumn{6}{|l|}{ Activity chamber } \\
\hline & & & & Genotype, $F(2,55)=2.491$ & $p>0.05$ \\
\hline \multirow[t]{2}{*}{ Total distance traveled(cm) } & $2807.3 \pm 197.9$ & $3445.5 \pm 236.0$ & $2842.9 \pm 140.5$ & Time, $F(5,275)=18.09$ & $p<0.0001$ \\
\hline & & & & Interaction, $F(5,275)=1.410$ & $p>0.05$ \\
\hline \multicolumn{6}{|l|}{ Steady speed rotarod } \\
\hline & & & & Genotype, $F(2,55)=1.971$ & $p>0.05$ \\
\hline \multirow[t]{2}{*}{ Latency to fall(sec) } & $27.417 \pm 2.635$ & $14.271 \pm 2.016$ & $20.033 \pm 3.363$ & Trial, $F(9,495)=9.686$ & $p<0.0001$ \\
\hline & & & & Interaction, $F(9,495)=1.002$ & $p>0.05$ \\
\hline \multicolumn{6}{|l|}{ Accelerating rotarod } \\
\hline & & & & Genotype, $F(2,17)=0.033$ & $p>0.05$ \\
\hline \multirow[t]{2}{*}{ Latency to fall(sec) } & $150.39 \pm 15.80$ & $155.49 \pm 14.76$ & $148.38 \pm 14.71$ & Trial, $F(2,34)=18.50$ & $p<0.0001$ \\
\hline & & & & Interaction, $F(2,34)=1.737$ & $p>0.05$ \\
\hline \multicolumn{6}{|l|}{ T-maze } \\
\hline$\% \mathrm{SA}$ & $44.837 \pm 2.456$ & $49.408 \pm 2.568$ & $50.113 \pm 2.181$ & $F(2,53)=1.417$ & $p>0.05$ \\
\hline$\%$ AAR & $36.794 \pm 2.114$ & $31.852 \pm 1.356$ & $31.123 \pm 2.096$ & $F(2,53)=2.408$ & $p>0.05$ \\
\hline$\%$ SAR & $7.354 \pm 1.1011$ & $7.840 \pm 1.198$ & $8.192 \pm 1.170$ & $F(2,53)=0.1350$ & $p>0.05$ \\
\hline \#arm entries & $27.963 \pm 1.778$ & $30.429 \pm 2.467$ & $33.333 \pm 2.131$ & $F(2,53)=1.742$ & $p>0.05$ \\
\hline Marble burying (\#) & $8 \pm 1.076$ & $10 \pm 1.742$ & $7.0 \pm 1.366$ & $F(2,53)=0.6750$ & $p>0.05$ \\
\hline \multicolumn{6}{|l|}{ EPM entries (\#) } \\
\hline & & & & Genotype, $F(2,54)=1.490$ & $p>0.05$ \\
\hline Closed arms & $9.5 \pm 0.946$ & $11.21 \pm 1.085$ & $9.8 \pm 1.147$ & Arm entries, $F(1,54)=147.8$ & $p<0.0001$ \\
\hline Open arms & $1.75 \pm 0.413$ & $3.21 \pm 0.594$ & $2.4 \pm 0.523$ & Interaction, $F(2,54)=0.06371$ & $p>0.05$ \\
\hline \multicolumn{6}{|l|}{ EPM duration (\%) } \\
\hline & & & & Genotype, $F(2,54)=0.0$ & $p>0.05$ \\
\hline Closed arms & $81.037 \pm 2.725$ & $63.268 \pm 5.701$ & $75.057 \pm 3.494$ & Arm duration, $F(2,108)=228.1$ & $p<0.0001$ \\
\hline Open arms & $8.102 \pm 2.276$ & $13.523 \pm 5.628$ & $8.736 \pm 2.077$ & Interaction, $F(2,108)=4.299$ & $p<0.005$ \\
\hline \multicolumn{6}{|l|}{ Sociability (sec) } \\
\hline & & & & Genotype, $F(2,53)=1.032$ & $p>0.05$ \\
\hline Side with mouse & $335.257 \pm 12.743$ & $340.71 \pm 11.666$ & $310.944 \pm 13.768$ & Chamber side, $F(2,106)=197.6$ & $p<0.0001$ \\
\hline Side with empty cup & $165.806 \pm 10.710$ & $144.05 \pm 10.953$ & $199.303 \pm 14.887$ & Interaction, $F(2,106)=2.493$ & $p<0.05$ \\
\hline \multicolumn{6}{|l|}{ Social novelty (sec) } \\
\hline & & & & Genotype, $F(2,53)=0.4669$ & $p>0.05$ \\
\hline Familiar mouse side & $239.276 \pm 15.473$ & $275.184 \pm 20.999$ & $239.899 \pm 24.126$ & Chamber side, $F(2,106)=47.53$ & $p<0.0001$ \\
\hline Novel mouse side & $256.915 \pm 14.165$ & $213.617 \pm 17.351$ & $256.977 \pm 24.069$ & Interaction, $F(2,106)=1.174$ & $p>0.05$ \\
\hline \multicolumn{6}{|l|}{ Sociability (sec) } \\
\hline & & & & Genotype, $F(2,53)=0.7821$ & $p>0.05$ \\
\hline Cup with mouse & $76.390 \pm 5.722$ & $72.092 \pm 5.533$ & $64.901 \pm 5.795$ & Cup time, $F(1,53)=212.2$ & $p<0.0001$ \\
\hline Empty cup & $13.486 \pm 1.589$ & $12.605 \pm 2.816$ & $14.391 \pm 2.338$ & Interaction, $F(2,53)=0.9274$ & $p>0.05$ \\
\hline \multicolumn{6}{|l|}{ Social novelty (sec) } \\
\hline & & & & Genotype, $F(2,53)=0.2960$ & $p>0.05$ \\
\hline Cup with familiar mouse & $25.686 \pm 3.224$ & $27.324 \pm 3.362$ & $25.807 \pm 3.938$ & Cup time, $F(1,53)=23.81$ & $p<0.0001$ \\
\hline Cup with novel Mouse & $46.11 \pm 3.858$ & $38.358 \pm 4.95$ & $41.836 \pm 4.558$ & Interaction, $F(2,53)=0.7666$ & $p>0.05$ \\
\hline
\end{tabular}


Table 2 Behavioral characterization of $\mathrm{WT}$, Met ${ }^{\mathrm{fx} /+} /$ Nestin $^{\text {cre }}$ Het, and Met $\mathrm{H}_{\mathrm{f} / \mathrm{fx}} / \mathrm{Nestin}^{\text {cre }} \mathrm{KO}$ mice (Continued)

Cue fear training (\%)

\begin{tabular}{|c|c|c|c|c|c|}
\hline & & & & Genotype, $F(2,21)=1.206$ & $p>0.05$ \\
\hline \multirow[t]{2}{*}{ Average freezing } & $27.681 \pm 3.621$ & $20.959 \pm 9.090$ & $24.956 \pm 2.421$ & Trial, $F(4,84)=31.76$ & $p<0.0001$ \\
\hline & & & & Interaction, $F(4,84)=0.8341$ & $p>0.05$ \\
\hline \multicolumn{6}{|c|}{ Cue fear context test (\%) } \\
\hline Average freezing & $25.501 \pm 2.778$ & $21.132 \pm 6.485$ & $24.408 \pm 4.978$ & $F(2,21)=0.201$ & $p>0.05$ \\
\hline \multicolumn{6}{|c|}{ Cue fear cue test (\%) } \\
\hline & & & & Genotype, $F(2,21)=3.156$ & $p>0.05$ \\
\hline \multirow[t]{2}{*}{ Average freezing } & $61.120 \pm 1.062$ & $72.072 \pm 2.478$ & $78.351 \pm 2.758$ & Trial, $F(9,189)=1.398$ & $p>0.05$ \\
\hline & & & & Interaction, $F(9,189)=0.9551$ & $p>0.05$ \\
\hline \multicolumn{6}{|c|}{ Cue fear extinction 1 (\%) } \\
\hline & & & & Genotype, $F(2,21)=1.032$ & $p>0.05$ \\
\hline \multirow[t]{2}{*}{ Average freezing } & $47.999 \pm 1.515$ & $60.181 \pm 2.219$ & $56.860 \pm 2.118$ & Trial, $F(9,189)=1.975$ & $p<0.05$ \\
\hline & & & & Interaction, $F(9,189)=0.6945$ & $p>0.05$ \\
\hline \multicolumn{6}{|l|}{ Extinction 2} \\
\hline & & & & Genotype, $F(2,21)=0.9524$ & $p>0.05$ \\
\hline \multirow[t]{2}{*}{ Average freezing } & $34.572 \pm 1.967$ & $40.725 \pm 3.196$ & $45.103 \pm 1.575$ & Trial, $F(9,189)=1.480$ & $p>0.05$ \\
\hline & & & & Interaction, $F(9,189)=1.196$ & $p>0.05$ \\
\hline \multicolumn{6}{|l|}{ Extinction 3} \\
\hline & & & & Genotype, $F(2,21)=0.2070$ & $p>0.05$ \\
\hline \multirow[t]{2}{*}{ Average freezing } & $30.900 \pm 2.513$ & $29.381 \pm 1.754$ & $36.167 \pm 1.686$ & Trial, $F(9,189)=1.026$ & $p>0.05$ \\
\hline & & & & Interaction, $F(9,189)=1.180$ & $p>0.05$ \\
\hline
\end{tabular}

Tukey's post hoc analysis revealed $\mathrm{Met}^{\mathrm{fx} / \mathrm{H}} / \mathrm{Nestin}^{\text {cre }}$ Het was significantly different from WT in both the closed arm and center time, with the $\mathrm{Met}^{\mathrm{fx} /+} / \mathrm{Nestin}^{\text {cre }}$ Het mice spending more time in the center portion of the arena (Fig. 4). Analysis of arm entries revealed there was no main effect for genotype, $p>0.05$. There was a main effect for location in the maze; all animals returned to the closed arms more often than open arms, $p<0.0001$. Furthermore, there was no interaction, $p>0.05$.

\section{Marble burying}

A one-way ANOVA revealed no significant differences in total number of marbles buried between genotypes, $p>0.05$ (Table 2).

\section{T-maze}

Distinct from the $M e t^{f x / f x} / E m x 1^{\text {cre }}$ KO mice, a one-way ANOVA found no differences in spontaneous alternation for any of the Nestin ${ }^{\text {cre }}$-derived genotypes, $p>0.05$ (Table 2). Neither alternate arm returns, same arm returns, nor total arm entries were significantly different between groups, $p>0.05$.

\section{Sociability and social novelty preference}

Two-way repeated measures ANOVA was conducted for sociability and social novelty preference scores using

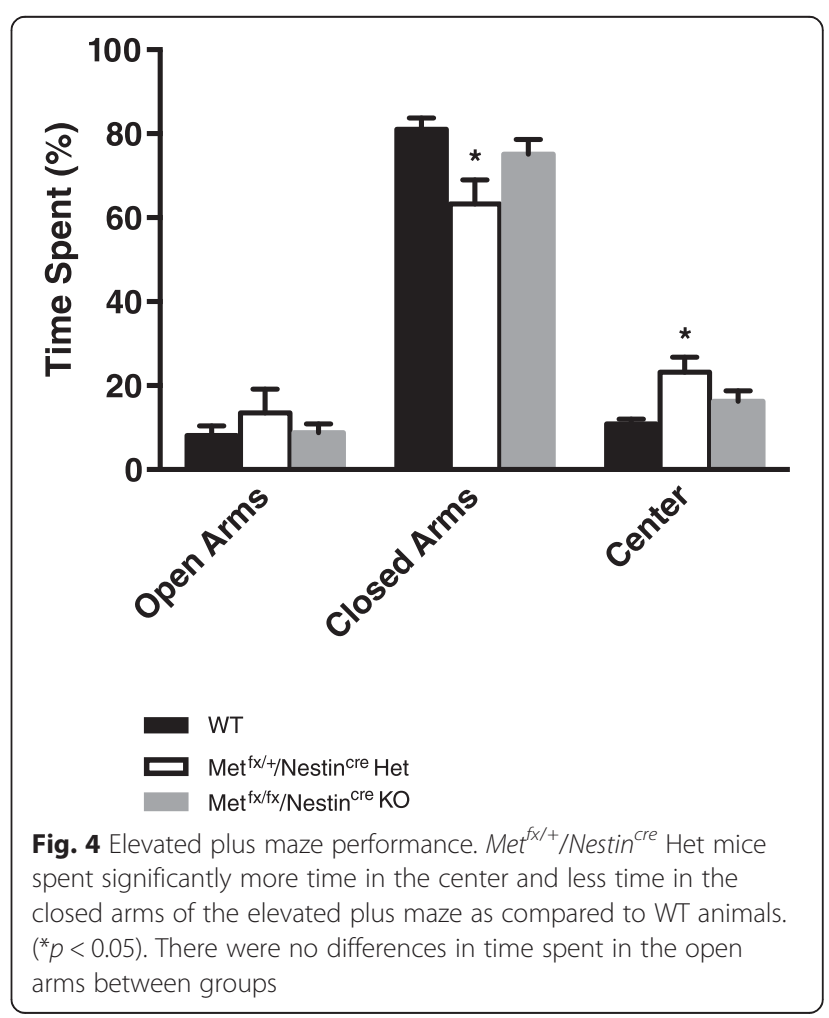


both chamber time and cup sniffing times for separate analyses (Table 2). For the chamber time during the sociability trial, there was no main effect for genotype, $p>0.05$. There was a main effect for chamber location during sociability, $p<0.0001$, with all animals spending more time in the chamber with the stimulus mouse. Interestingly, there was an interaction effect, $p<0.05$. A Tukey's post hoc analysis revealed Met ${ }^{f x / f x} / \mathrm{Nestin}^{\text {cre }} \mathrm{KO}$ animals spent significantly more time in the chamber with an empty wire cup than the Met $t^{f x /+} / \mathrm{Nestin}^{\text {cre }}$ Het animals (Fig. 5). For chamber time during the social novelty preference trial, there was no main effect for genotype, $p>0.05$. There was a main effect for chamber location during the test with all animals spending more time on the side of the chamber where the novel mouse was located, $p<0.0001$. Furthermore, there was no interaction effect, $p>0.05$. When comparing cup-sniffing times, there were no differences either in sociability or in social novelty preference scores between the groups. During the sociability trial, there was no main effect for genotype, $p>0.05$. Both groups of animals spent more time sniffing the cup with the stimulus mouse, $p<0.0001$. Furthermore, there was no interaction between genotype and cup sniffing, $p>0.05$. During the social novelty preference trial, there was no main effect for genotype, $p>0.05$. All animals spent more time sniffing the novel mouse, $p<0.0001$. Additionally, there was no interaction between genotype and cup sniffing, $p>0.05$.

\section{Olfactory dishabituation}

There were no significant differences between genotypes during olfactory dishabituation, $p>0.05$ (Table 2). There was a significant main effect for trial, $p<0.0001$, with

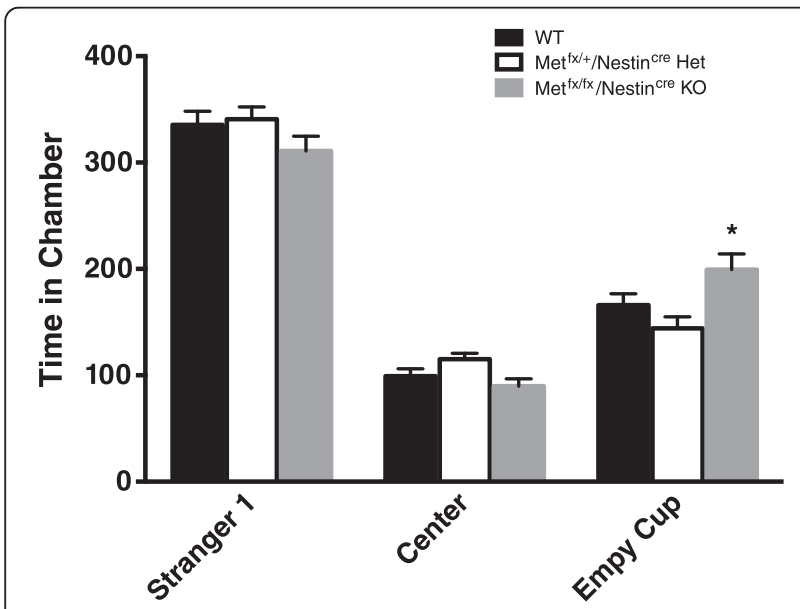

Fig. 5 Sociability in the three-chamber task. While all animals demonstrated sociability (more time in chamber with stranger mouse than empty cup), Met ff/fx $_{\text {NNestin }}^{\text {cre }} \mathrm{KO}$ mice spent significantly more time in the chamber with the empty wire cup compared to Met $\mathrm{f}^{\mathrm{fx} /+} / \mathrm{Nestin}^{\text {cre }}$ Het animals. ( $\left.{ }^{*} p<0.05\right)$. There were no significant differences in center time or in the time spent in the chamber with the stranger mouse the social trials eliciting more sniffing time. Furthermore, there was no interaction effect between genotype and sniffing behavior, $p>0.05$, with all animals showing similar sniffing behaviors across odorants.

\section{Contextual fear conditioning}

In contrast to the $M e t^{f x / f x} / E m x 1^{\text {cre }} \mathrm{KO}$ mice, there were significant differences between genotypes for contextual fear conditioning, $F(2,53)=5.748, p<0.01$ (Fig. 6). Additionally, there was a main effect for fear conditioning phase, $F(2,106)=152.3, p<0.0001$, with animals displaying significantly increased freezing during the training session and retention test compared to baseline. Furthermore, there was also a significant interaction effect, $F(2,106)=5.209, p<0.001$. Tukey's multiple comparisons test revealed Met $t^{f x /+} / \mathrm{Nestin}^{\text {cre }}$ Het mice exhibited significantly impaired freezing during contextual fear training compared to WT $(p<0.05)$, while $M e t^{f x / f x} /$ Nestin $^{\text {cre }} \mathrm{KO}$ animals display a non-significant trend toward reduced freezing. Additionally, Tukey's multiple comparison test also revealed that both the $\mathrm{Met}^{f x /+} / \mathrm{Nestin}^{\text {cre }}$ Het and Met ${ }^{f x / f x} / \mathrm{Nestin}^{\text {cre }} \mathrm{KO}$ animals showed significantly blunted freezing during the retention test compared to $\mathrm{WT}, p<0.05$.

\section{Cued (auditory) fear conditioning}

Training, testing, and extinction trials were analyzed separately with two-way repeated measures ANOVAs to determine differences in rates of learning across genotypes (Table 2). For the acquisition of cued fear conditioning, there was no main effect for genotype, $p>0.05$. There was a main effect for trial, $p<0.0001$, with all animals showing increased freezing times to the presentation of the cue with more footshock exposures. There was no interaction effect between genotype and trials, $p>0.05$. The following day, there was very little freezing during the context test.

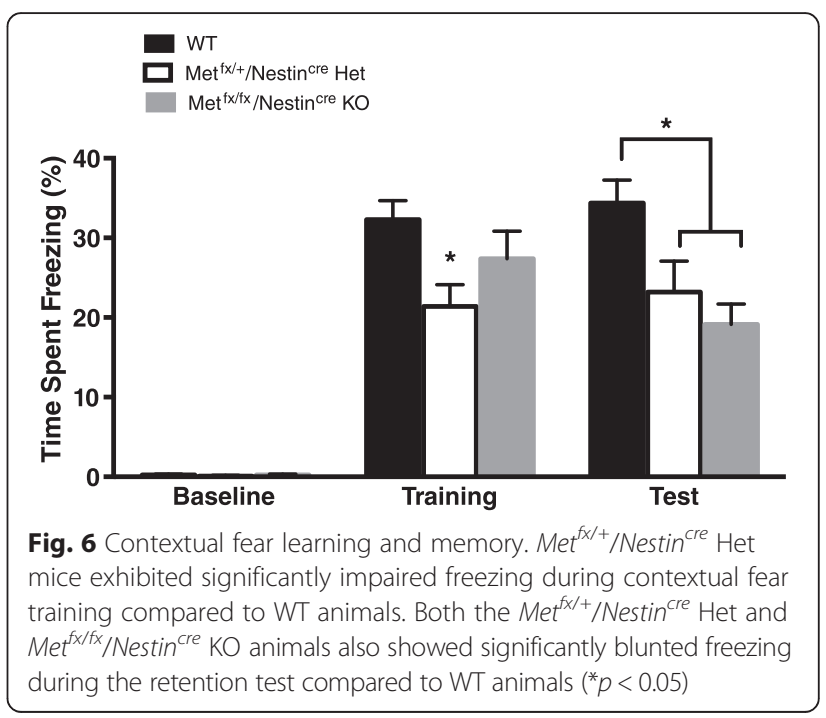


There were no differences in the context test between genotypes, $p>0.05$. During the cue test, however, animals showed significant freezing times. There was no main effect for genotype, $p>0.05$. There also was no main effect for trial, $p>0.05$, with all animals showing consistent freezing across trials. Furthermore, there was no genotype by trial interaction, $p>0.05$. During all three extinction tests, there was no main effect for genotype, $p>0.05$. Only during the first extinction test was there a main effect for trial, $p<0.05$, with all animals showing decreased freezing across trials. The remaining two extinctions showed no main effect for trial, $p>0.05$. Furthermore, for all three extinction tests, there was no genotype by trial interaction, $p>0.05$.

\section{Conclusions}

Here, we report that genetic disruption of Met expression results in distinct phenotypes depending upon the neuronal populations that are targeted. The findings are not surprising, given that multiple studies across species have shown that disruption of MET signaling genetically results in distinct cellular phenotypes, depending upon the central or peripheral neural structure in which gene expression is manipulated $[3,5,8,15,30,50]$. For example, our morphological and electrophysiological studies revealed differences in synapse development that alter excitatory drive onto deep layer pyramidal neurons from input located in superficial layers in the neocortex and early excitatory synapse maturation in the hippocampus. It is important to emphasize that specific altered phenotypes are evident in only select subpopulations of neurons. For example, increased excitatory drive is expressed by a subset of layer V cortical-striatal neurons, but not cortico-pontine neurons [15]. Moreover, different cell populations appear to be more or less sensitive to gene dose $[8,15]$. These data are consistent with the hypothesis that, in the forebrain, MET signaling can influence developmental processes that underlie quantitative temporal and spatial aspects of connectivity. However, disruption in signaling alone is insufficient to create dramatic transformations such as those observed with genes that cause syndromic disorders that often are accompanied by intellectual disability and other severe impairments. Our hypothesis is also consistent with the recent discovery of a pedigree in which a heterozygous loss-of-function mutation of MET results in ASD or social-communication diagnosis, but no intellectual disability. Our current behavioral findings, subtle in nature, are also consistent with a modulatory role for $M E T$ gene dose in human brain growth (Hedrick, 2012). Human neuroimaging studies showed that the functional "C" promoter allele, which reduces gene transcription, correlates with reduced connectivity and functional activation of circuits when looking at emotional faces, even in the typically developing population [25].

The present study was the first attempt to reveal the behavioral impact of altering Met expression in the mouse. Unique to the study design was examination of the impact of integrated circuitry using two distinct driver lines to eliminate Met expression. We first eliminated Met using $E_{m x} I^{\text {cre }}$ to eliminate functional signaling from neurons derived from the dorsal pallium. These cells give rise in part to circuitry involved in mediating social and emotional behaviors disrupted in ASD. We also eliminated Met using the Nestin ${ }^{\text {cre }}$ driver, in which Met was deleted from all neural cells, thereby presumably impacting behaviors more globally, not only those considered core ASD behaviors. Because there are fundamental differences in the neocortical expression patterns of MET in primates compared to mice $[10,13,14]$, with Met being more widespread in the rodent, it was not clear whether any core social-communication deficits that are associated with the $\mathrm{C}$ promoter allele would be altered in the mouse models. We therefore used a large repertoire of behavioral tasks, including basic motor function, probes of affective state, social proclivity, and complex learning that extend beyond mouse behaviors that have human correlates implicated in ASD. These additional behaviors, such as activity, anxiety, and attention, are not diagnostic of ASD but can be expressed by subgroups of children with the diagnosis [51-53].

In general, the $M e t^{f x / f x} / E m x 1^{\text {cre }} \mathrm{KO}$ animals display hypoactivity across several behavioral tasks, but this does not appear to reflect impaired coordination, as their performance on the rotarod was significantly better than their WT littermates. Additionally, these animals display blunted spontaneous alternation, indicative of impaired spatial working memory. These animals show no differences in olfactory dishabituation, sociability, and social novelty preference, and their learning and retention of memory in fear conditioning was intact. The more global deletion of Met generated some surprising results but readily replicated in separate cohorts. First, the $M e t^{f x /+f f x / f x} / N_{e s t i n}{ }^{c r e}$ Het and KO lines do not express differences in locomotion or spontaneous alternation. In fact, the only behavioral task in which these animals differ from their WT littermates is contextual fear conditioning. Second, the more severe deficits measured in $\mathrm{Met}^{f x /+} / \mathrm{Nestin}^{\text {cre }}$ Het animals compared to the full KO or WT was unexpected. Het mice exhibited disruptions in both fear learning and memory, whereas the $M e t^{f x / f x} /$ Nestin $^{\text {cre }} \mathrm{KO}$ animals demonstrate a disruption only in fear memory. While not statistically significant, the same trend for more disruptions in Het mice is present in both rotarod and activity chamber performance. As already noted, this was not seen with the heterozygous $M e t^{f x /+} / E m x 1^{\text {cre }}$ mice, as they do not show 
any behavioral differences from WT in the tasks used here (data not shown). Interestingly, Het and $\mathrm{KO}$ mice created with the same $E m x 1^{\text {Cre }}$ driver, however, do exhibit similar increases in excitatory drive on a subset of layer 5 pyramidal cells [15], suggesting that more targeted, advanced behavioral tasks that probe intracortical connectivity in mice would need to be used to demonstrate cellular and whole animal functional correlates.

In contrast to the current report, most behavioral studies do not examine potential gene dose effects. When analyzed, Het animals typically are reported as not different from WT or intermediate between complete knockouts and controls [54-59]. There are several explanations for the more robust Het phenotype observed here. It is possible that $\mathrm{Met}^{f \mathrm{fx} /+} / \mathrm{Nestin}^{\text {cre }}$ Het mice, which express approximately $50 \%$ of MET protein (Additional file 1), fail to exhibit compensatory mechanisms that may occur in complete $\mathrm{Met}^{f x / f x} / \mathrm{Nestin}^{\text {cre }} \mathrm{KO}$ animals in which the early complete absence of MET signaling generates adaptations (Fig. 7). Certain experimental perturbations have revealed this phenomenon, such as the lack of phenotype when a gene is deleted genetically, but robust disruptions when expression is reduced partially in a subset of cells [60, 61]. In addition, even for genes that cause syndromic disorders, behavioral studies are complex due to issues of strain background, the genetic strategies for deletion, variation in testing environments across laboratories, and even testers [62-64].

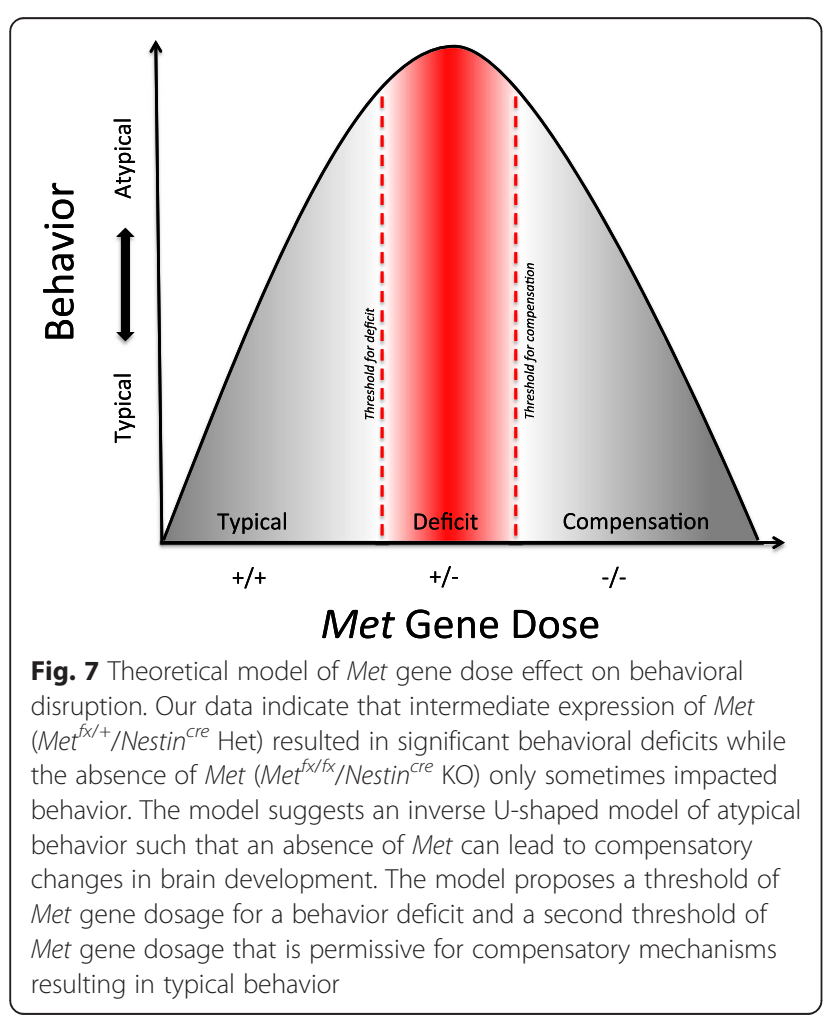

Inverted " $U$ " outcomes are common, in which the same physiological response or behavioral performance occurs with low or high amounts of hormones, neurotransmitters, or psychological stress [65-69]. Here, because the MET receptor tyrosine kinase converges on downstream intracellular systems (ERK and PI3 kinase) that mediate many receptor signaling cascades [70], it is possible that an imbalance in signaling during development is as, or more, detrimental than no signaling at all via this receptor. It is interesting that for ASD and intellectual disability, disruptions of the intracellular downstream components from multiple receptors are dominant $[71,72]$. If such adaptive differences do occur, it is likely that there are cell type-specific effects (as seen electrophysiologically between neocortical [15] and CA1 hippocampal [8] pyramidal cells), because differences between WT and $M e t^{f x /+} / E m x I^{c r e}$ heterozygous mice were not obtained in the behavioral assays used here. It is important to note that these classic probes of behavior may not be sufficiently sensitive to detect differences in information processing due to altered cortical circuitry.

Finally, our studies of Met/MET to date have focused on understanding the role of the receptor tyrosine kinase itself in mediating typical behavioral performance. Studies utilizing ethologically relevant tasks that examine complex information processing may reveal further deficits. Additionally, a combination of genetic disruption and environmental factors will also need to be examined. For example, in humans, the $M E T$ functional $\mathrm{C}$ allele has been associated with environmental factors, such as ultrafine particle pollutants, that increase risk for ASD [22, 73, 74]. Thus, combining behavioral assays that target forebrain and hindbrain circuits, the latter being where Met is expressed in autonomic circuits prenatally [75], with human population-relevant environmental exposures may yield important avenues for discovering mechanisms of action.

\section{Additional file}

Additional file 1: Met protein reduction in $\mathrm{Met}^{\mathrm{fx} /+} / \mathrm{Nestin}{ }^{\mathrm{cre}}$ heterozygous mice. Representative blots of tissue homogenates for P21 frontal cortex were prepared for Western blots to examine MET expression according to Judson [11] with modifications. Note the reduction in the mature Met receptor (145 kd band) in Met $^{\mathrm{f} / \mathrm{t}} / \mathrm{Nestin}^{\mathrm{cre}}$ Het mice compared to WT. Reduction was consistent and replicated in more than 10 mice per line.

\section{Abbreviations}

AAR: alternate arm return; ANOVA: analysis of variance; ASD: autism spectrum disorder; CA1: cornu ammonis 1 region of hippocampus; Cm: centimeter; dB: decibel; EPM: elevated plus maze; ERK1: extracellular kinase 1;

Het: heterozygous; kHz: kilohertz; KO: knockout; mA: milliamp; P: postnatal day; PI3: phosphoinositide 3; RPM: revolutions per minute; SA: spontaneous alternation; SAR: same arm return; WT: wildtype. 


\section{Competing interests}

The authors declare that they have no competing interests.

\section{Authors' contributions}

BT carried out the behavioral studies, helped conceive the study, participated in its design and coordination, and drafted the manuscript. PL conceived of the study, participated in its design and coordination, and helped draft the manuscript. Both authors read and approved the final manuscript.

\section{Acknowledgements}

This research was supported by $\mathrm{NIH}$ grant $\mathrm{MH067842}(\mathrm{PL})$ and a grant from the Simons Foundation for Autism Research Initiative (PL). The authors thank Williams Rodriguez and Amanda Whipple for their excellent technical assistance. We also thank Drs. Kathie Eagleson, Allison Knoll, and Daniel Campbell for their helpful comments during the studies and in writing the manuscript.

\section{Author details}

${ }^{1}$ Chan Division of Occupational Science and Occupational Therapy, Herman Ostrow School of Dentistry, University of Southern California, Los Angeles, CA 90089, USA. ${ }^{2}$ Institute for the Developing Mind, Children's Hospital of Los Angeles, Keck School of Medicine, University of Southern California, Los Angeles, CA 90027, USA. 3Department of Pediatrics, Children's Hospital of Los Angeles, Keck School of Medicine, University of Southern California, Los Angeles, CA 90027, USA.

Received: 9 June 2015 Accepted: 20 October 2015

\section{Published online: 01 November 2015}

\section{References}

1. Bottaro DP, Rubin JS, Faletto DL, Chan AM, Kmiecik TE, Vande Woude GF, et al. Identification of the hepatocyte growth factor receptor as the c-met proto-oncogene product. Science. 1991;251(4995):802-4.

2. Graveel CR, Tolbert D, Vande Woude GF. MET: a critical player in tumorigenesis and therapeutic target. Cold Spring Harb Perspect Biol. 2013;5(7):a009209.

3. Judson MC, Eagleson KL, Wang L, Levitt P. Evidence of cell-nonautonomous changes in dendrite and dendritic spine morphology in the met-signalingdeficient mouse forebrain. J Comp Neurol. 2010;518(21):4463-78. doi:10.1002/cne.22467.

4. Lim CS, Walikonis RS. Hepatocyte growth factor and c-Met promote dendritic maturation during hippocampal neuron differentiation via the Akt pathway. Cell Signal. 2008;20(5):825-35. doi:10.1016/j.cellsig.2007.12.013.

5. Tyndall SJ, Patel SJ, Walikonis RS. Hepatocyte growth factor-induced enhancement of dendritic branching is blocked by inhibitors of $\mathrm{N}$-methylD-aspartate receptors and calcium/calmodulin-dependent kinases. J Neurosci Res. 2007;85(11):2343-51.

6. Qiu S, Aldinger KA, Levitt P. Modeling of autism genetic variations in mice: focusing on synaptic and microcircuit dysfunctions. Dev Neurosci. 2012;34(2-3):88-100.

7. Peng $Y$, Huentelman M, Smith C, Qiu S. MET receptor tyrosine kinase as an autism genetic risk factor, Bioinformatics of behavior: part 2. 1st ed. Philadelphia: Elsevier Inc; 2014. p. 135-65.

8. Qiu S, Lu Z, Levitt P. MET receptor tyrosine kinase controls dendritic complexity, spine morphogenesis, and glutamatergic synapse maturation in the hippocampus. J Neurosci. 2014;34(49):16166-79.

9. Eagleson KL, Milner TA, Xie Z, Levitt P. Synaptic and extrasynaptic location of the receptor tyrosine kinase met during postnatal development in the mouse neocortex and hippocampus. J Comp Neurol. 2013;521(14):3241-59. doi:10.1002/cne.23343.

10. Judson MC, Amaral DG, Levitt P. Conserved subcortical and divergent cortical expression of proteins encoded by orthologs of the autism risk gene MET. Cereb Cortex. 2011;21(7):1613-26. doi:10.1093/cercor/bhq223.

11. Judson MC, Bergman MY, Campbell DB, Eagleson KL, Levitt P. Dynamic gene and protein expression patterns of the autism-associated met receptor tyrosine kinase in the developing mouse forebrain. J Comp Neurol. 2009:513(5):511-31. doi:10.1002/cne.21969.

12. Eagleson $\mathrm{KL}$, Campbell DB, Thompson BL, Bergman MY, Levitt P. The autism risk genes MET and PLAUR differentially impact cortical development. Autism Res. 2010;4(1):68-83.

13. Mukamel Z, Konopka G, Wexler E, Osborn GE, Dong H, Bergman MY, et al. Regulation of MET by FOXP2, genes implicated in higher cognitive dysfunction and autism risk. J Neurosci. 2011;31(32):11437-42. doi:10.1523/JNEUROSCI.0181-11.2011.

14. Bernard A, Lubbers LS, Tanis KQ, Luo R, Podtelezhnikov AA, Finney EM, et al. Transcriptional architecture of the primate neocortex. Neuron. 2012;73(6):1083-99.

15. Qiu S, Anderson CT, Levitt P, Shepherd GM. Circuit-specific intracortical hyperconnectivity in mice with deletion of the autism-associated Met receptor tyrosine kinase. J Neurosci. 2011;31(15):5855-64. doi:10.1523/JNEUROSCI.6569-10.2011.

16. Campbell DB, Li C, Sutcliffe JS, Persico AM, Levitt P. Genetic evidence implicating multiple genes in the MET receptor tyrosine kinase pathway in autism spectrum disorder. Autism Res. 2008;1(3):159-68.

17. Jackson PB, Boccuto L, Skinner C, Collins JS, Neri G, Gurrieri F, et al. Further evidence that the rs $1858830 \mathrm{C}$ variant in the promoter region of the MET gene is associated with autistic disorder. Autism Res. 2009;2(4):232-6.

18. Thanseem I, Nakamura K, Miyachi T, Toyota T, Yamada S, Tsujii M, et al. Further evidence for the role of MET in autism susceptibility. Neurosci Res. 2010;68(2):137-41.

19. Abrahams BS, Arking DE, Campbell DB, Mefford HC, Morrow EM, Weiss LA, et al. SFARI Gene 2.0: a community-driven knowledgebase for the autism spectrum disorders (ASDs). Molecular Autism. 2013;4(1):1.

20. Campbell DB, D'Oronzio R, Garbett K, Ebert PJ, Mirnics K, Levitt P, et al. Disruption of cerebral cortex MET signaling in autism spectrum disorder. Ann Neurol. 2007;62(3):243-50. doi:10.1002/ana.21180.

21. Campbell DB, Sutcliffe JS, Ebert PJ, Militerni R, Bravaccio C, Trillo S, et al. A genetic variant that disrupts MET transcription is associated with autism. Proc Natl Acad Sci U S A. 2006;103(45):16834-9. doi:10.1073/ pnas.0605296103.

22. Heuer L, Braunschweig D, Ashwood P, Van de Water J, Campbell DB. Association of a MET genetic variant with autism-associated maternal autoantibodies to fetal brain proteins and cytokine expression. Translational Psychiatry. 2011;1(10):e48-7.

23. Lambert N, Wermenbol V, Pichon B, Acosta S, van den Ameele J, Perazzolo

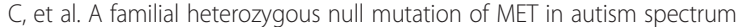
disorder. Autism Res. 2014;7(5):617-22.

24. Campbell DB, Warren D, Sutcliffe JS, Lee EB, Levitt P. Association of MET with social and communication phenotypes in individuals with autism spectrum disorder. Am J Med Genet. 2009. doi:10.1002/ajmg.b.30998.

25. Rudie JD, Hernandez LM, Brown JA, Beck-Pancer D, Colich NL, Gorrindo P, et al. Autism-associated promoter variant in MET impacts functional and structural brain networks. Neuron. 2012;75(5):904-15. doi:10.1016/j.neuron.2012.07.010.

26. Hedrick A, Lee Y, Wallace GL, Greenstein D, Clasen L, Giedd JN, et al. Autism risk gene MET variation and cortical thickness in typically developing children and adolescents. Autism Res. 2012;5(6):434-9. doi:10.1002/aur.1256.

27. Ey E, Leblond CS, Bourgeron T. Behavioral profiles of mouse models for autism spectrum disorders. Autism Res. 2011;4(1):5-16.

28. Crawley JN. Behavioral phenotyping strategies for mutant mice. Neuron. 2008;57(6):809-18.

29. Hamilton SM, Spencer CM, Harrison WR, Yuva-Paylor LA, Graham DF, Daza RAM, et al. Multiple autism-like behaviors in a novel transgenic mouse model. Behav Brain Res. 2011;218(1):29-41.

30. Ebens A, Brose K, Leonardo ED, Hanson MG, Bladt F, Birchmeier C, et al. Hepatocyte growth factor/scatter factor is an axonal chemoattractant and a neurotrophic factor for spinal motor neurons. Neuron. 1996;17(6):1157-72.

31. Gorski JA, Talley T, Qiu M, Puelles L, Rubenstein JL, Jones KR. Cortical excitatory neurons and glia, but not GABAergic neurons, are produced in the Emx1-expressing lineage. J Neurosci. 2002;22(15):6309-14.

32. Krysko O, Hulshagen L, Janssen A, Schütz G, Klein R, De Bruycker M, et al. Neocortical and cerebellar developmental abnormalities in conditions of selective elimination of peroxisomes from brain or from liver. J Neurosci Res. 2007;85(1):58-72.

33. Huh CG, Factor VM, Sanchez A, Uchida K, Conner EA, Thorgeirsson SS Hepatocyte growth factor/c-met signaling pathway is required for efficient liver regeneration and repair. Proc Natl Acad Sci U S A. 2004;101(13):4477-82.

34. Crawley JN. Behavioral phenotyping of transgenic and knockout mice: experimental design and evaluation of general health, sensory functions, motor abilities, and specific behavioral tests. Brain Res. 1999;835(1):18-26.

35. Tapp JT, Wehby JH, Ellis D. MOOSES: a multi-option observation system for experimental studies. Behav Res Methods, Instruments, Computers. 1995;27:25-31. 
36. Thomas A, Burant A, Bui N, Graham D, Yuva-Paylor LA, Paylor R. Marble burying reflects a repetitive and perseverative behavior more than novelty-induced anxiety. Psychopharmacology (Berl). 2009;204(2):361-73. doi:10.1007/s00213-009-1466-y.

37. Hughes RN. The value of spontaneous alternation behavior (SAB) as a test of retention in pharmacological investigations of memory. Neurosci Biobehav Rev. 2004;28(5):497-505. doi:10.1016/j.neubiorev.2004.06.006.

38. Lalonde R. The neurobiological basis of spontaneous alternation. Neurosci Biobehav Rev. 2002;26(1):91-104.

39. Katz RJ, Chudler R. Y-maze behavior after an analog of ACTH 4-9, evidence for an attentional alteration. Psychopharmacology. 1980;71(1):95-6.

40. Kokkinidis $L$, Anisman $H$. Interaction between cholinergic and catecholaminergic agents in a spontaneous alternation task. Psychopharmacology. 1976;48(3):261-70

41. Ueno K, Togashi H, Matsumoto M, Ohashi S, Saito H, Yoshioka M. Alpha4beta2 nicotinic acetylcholine receptor activation ameliorates impairment of spontaneous alternation behavior in stroke-prone spontaneously hypertensive rats, an animal model of attention deficit hyperactivity disorder. J Pharmacol Exp Ther. 2002;302(1):95-100.

42. Ueno Kl, Togashi H, Mori K, Matsumoto M, Ohashi S, Hoshino A, et al. Behavioural and pharmacological relevance of stroke-prone spontaneously hypertensive rats as an animal model of a developmental disorder. Behav Pharmacol. 2002;13(1):1-13.

43. Wall PM, Blanchard RJ, Markham C, Yang M, Blanchard DC. Infralimbic D1 receptor agonist effects on spontaneous novelty exploration and anxiety-like defensive responding in CD-1 mice. Behav Brain Res. 2004;152(1):67-79. doi:10.1016/j.bbr.2003.09.035.

44. Wall PM, Blanchard RJ, Yang M, Blanchard DC. Infralimbic D2 receptor influences on anxiety-like behavior and active memory/attention in CD-1 mice. Prog Neuro-Psychopharmacol Biol Psychiatry. 2003;27(3):395-410. doi:10.1016/S0278-5846(02)00356-1.

45. Thompson BL, Levitt $P$, Stanwood GD. Prenatal cocaine exposure specifically alters spontaneous alternation behavior. Behav Brain Res. 2005;164(1):107-16.

46. Bielsky IF, Hu SB, Ren X, Terwilliger EF, Young LJ. The V1a vasopressin receptor is necessary and sufficient for normal social recognition: a gene replacement study. Neuron. 2005:47(4):503-13. doi:10.1016/ j.neuron.2005.06.031.

47. Ferguson JN, Young LJ, Hearn EF, Matzuk MM, Insel TR, Winslow JT. Social amnesia in mice lacking the oxytocin gene. Nat Genet. 2000;25(3):284-8. doi:10.1038/77040

48. Ferkin MH, Li HZ. A battery of olfactory-based screens for phenotyping the social and sexual behaviors of mice. Physiol Behav. 2005;85(4):489-99. doi:10.1016/j.physbeh.2005.05.014.

49. Moy SS, Nadler JJ, PEREZ A, Barbaro RP, Johns JM, Magnuson TR, et al. Sociability and preference for social novelty in five inbred strains: an approach to assess autistic-like behavior in mice. Genes Brain Behav. 2004;3(5):287-302.

50. Gutierrez H, Dolcet X, Tolcos M, Davies A. HGF regulates the development of cortical pyramidal dendrites. Development. 2004;131(15):3717-26.

51. Maski KP, Jeste SS, Spence SJ. Common neurological co-morbidities in autism spectrum disorders. Curr Opin Pediatr. 2011;23(6):609-15. doi:10.1097/MOP.0b013e32834c9282.

52. Bauman ML. Medical comorbidities in autism: challenges to diagnosis and treatment. Neurotherapeutics : J American Soc Experimental NeuroTherapeutics. 2010;7(3):320-7. doi:10.1016/j.nurt.2010.06.001.

53. Croen LA, Zerbo O, Qian Y, Massolo ML, Rich S, Sidney S, et al. The health status of adults on the autism spectrum. Autism : Int Journal Res Pract. 2015. doi:10.1177/1362361315577517.

54. Wohr M, Silverman JL, Scattoni ML, Turner SM, Harris MJ, Saxena R, et al. Developmental delays and reduced pup ultrasonic vocalizations but normal sociability in mice lacking the postsynaptic cell adhesion protein neuroligin2. Behav Brain Res. 2013;251:50-64. doi:10.1016/j.bbr.2012.07.024.

55. Pagani JH, Williams Avram SK, Cui Z, Song J, Mezey E, Senerth JM, et al. Raphe serotonin neuron-specific oxytocin receptor knockout reduces aggression without affecting anxiety-like behavior in male mice only. Genes Brain Behav. 2015;14(2):167-76. doi:10.1111/gbb.12202.

56. Mosienko V, Beis D, Alenina N, Wohr M. Reduced isolation-induced pup ultrasonic communication in mouse pups lacking brain serotonin. Molecular Autism. 2015;6:13. doi:10.1186/s13229-015-0003-6.
57. Joeyen-Waldorf J, Edgar N, Sibille E. The roles of sex and serotonin transporter levels in age- and stress-related emotionality in mice. Brain Res 2009;1286:84-93. doi:10.1016/j.brainres.2009.06.079.

58. Bi W, Yan J, Shi X, Yuva-Paylor LA, Antalffy BA, Goldman A, et al. Rai1 deficiency in mice causes learning impairment and motor dysfunction, whereas Rai1 heterozygous mice display minimal behavioral phenotypes. Hum Mol Genet. 2007;16(15):1802-13. doi:10.1093/hmg/ddm128.

59. de Rezende VB, Rosa DV, Comim CM, Magno LA, Rodrigues AL, Vidigal P, et al. NCS-1 deficiency causes anxiety and depressive-like behavior with impaired non-aversive memory in mice. Physiol Behav. 2014;130:91-8. doi:10.1016/j.physbeh.2014.03.005.

60. Bai J, Ramos RL, Ackman JB, Thomas AM, Lee RV, LoTurco JJ. RNAi reveals doublecortin is required for radial migration in rat neocortex. Nat Neurosci. 2003;6(12):1277-83. doi:10.1038/nn1153.

61. Corbo JC, Deuel TA, Long JM, LaPorte P, Tsai E, Wynshaw-Boris A, et al. Doublecortin is required in mice for lamination of the hippocampus but not the neocortex. J Neurosci. 2002;22(17):7548-57.

62. Sorge RE, Martin LJ, Isbester KA, Sotocinal SG, Rosen S, Tuttle AH, et al. Olfactory exposure to males, including men, causes stress and related analgesia in rodents. Nat Methods. 2014;1-6.

63. Spencer CM, Alekseyenko O, Hamilton SM, Thomas AM, Serysheva E, Yuva-Paylor LA, et al. Modifying behavioral phenotypes in Fmr1KO mice: genetic background differences reveal autistic-like responses. Autism Res. 2011:4(1):40-56.

64. Jiang $Y$, Ehlers M. Modeling autism by SHANK gene mutations in mice. Neuron. 2013;78:8-27.

65. Diamond DM, Campbell AM, Park CR, Halonen J, Zoladz PR. The temporal dynamics model of emotional memory processing: a synthesis on the neurobiological basis of stress-induced amnesia, flashbulb and traumatic memories, and the Yerkes-Dodson law. Neural Plasticity. 2007;2007:60803. doi:10.1155/2007/60803.

66. Halpin B. Effects of arousal level on olfactory sensitivity. Percept Mot Skills. 1978:46(3 Pt 2):1095-102. doi:10.2466/pms.1978.46.3c.1095.

67. Mattay VS, Goldberg TE, Fera F, Hariri AR, Tessitore A, Egan MF, et al. Catechol O-methyltransferase val158-met genotype and individual variation in the brain response to amphetamine. Proc Natl Acad Sci U S A. 2003;100(10):6186-91. doi:10.1073/pnas.0931309100.

68. Cools R, D'Esposito M. Inverted-U-shaped dopamine actions on human working memory and cognitive control. Biol Psychiatry. 2011;69(12):e113-25. doi:10.1016/j.biopsych.2011.03.028.

69. Diamond DM, Bennett MC, Fleshner M, Rose GM. Inverted-U relationship between the level of peripheral corticosterone and the magnitude of hippocampal primed burst potentiation. Hippocampus. 1992;2(4):421-30. doi:10.1002/hipo.450020409.

70. Lemmon MA, Schlessinger J. Cell signaling by receptor tyrosine kinases. Cell. 2010;141(7):1117-34

71. Berg JM, Geschwind DH. Autism genetics: searching for specificity and convergence. Genome Biol. 2012;13(7):247. doi:10.1186/gb4034.

72. Levitt $P$, Campbell DB. The genetic and neurobiologic compass points toward common signaling dysfunctions in autism spectrum disorders. J Clin Invest. 2009;119(4):747-54. doi:10.1172/JCl37934.

73. Sheng L, Ding X, Ferguson M, McCallister M, Rhoades R, Maguire M, et al. Prenatal polycyclic aromatic hydrocarbon exposure leads to behavioral deficits and downregulation of receptor tyrosine kinase. MET Toxicological Sci. 2010;118(2):625-34

74. Volk HE, Kerin T, Lurmann F, Hertz-Picciotto I, McConnell R, Campbell DB. Autism spectrum disorder: interaction of air pollution with the MET receptor tyrosine kinase gene. Epidemiology. 2014;25(1):44-7. doi:10.1097/ EDE.0000000000000030.

75. Wu HH, Levitt P. Prenatal expression of MET receptor tyrosine kinase in the fetal mouse dorsal raphe nuclei and the visceral motor/sensory brainstem. Dev Neurosci. 2013;35(1):1-16. doi:10.1159/000346367. 